\title{
EFFECTS OF RECIRCULATION IN ANAEROBIC BAFFLED REACTORS
}

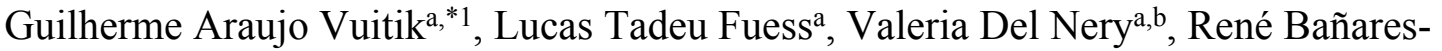
Alcántara ${ }^{\mathrm{c}}$, Eduardo Cleto Pires ${ }^{\mathrm{a}, \mathrm{b}}$

aBiological Processes Laboratory, São Carlos School of Engineering, University of São Paulo (LPB/EESC/USP). Av. João Dagnone 1100, São Carlos, São Paulo 13563-120, Brasil. Emails: guilhermevuitik@gmail.com; 1tfuess@alumni.usp.br

bDepartment of Hydraulics and Sanitary Engineering, São Carlos School of Engineering, University of São Paulo (SHS/EESC/USP). Av. Trabalhador São-Carlense 400, São Carlos, São Paulo 13566-590, Brasil. E-mails: vdelnery@terra.com.br, ecpires@sc.usp.br cDepartment of Engineering Science, University of Oxford. Parks Road, Oxford OX1 3PJ, United Kingdom. E-mail: rene.banares@eng.ox.ac.uk

(*) Corresponding author

\section{Abbreviations}

ABR

$\mathrm{AD}$

BOD

COD

CSTR

IA

OLR

PA

SS

UASB

VFA
Anaerobic baffled reactor

Anaerobic digestion

Biochemical oxygen demand

Chemical oxygen demand

Completely stirred tank reactor

Intermediate alkalinity

Organic loading rate

Partial alkalinity

Suspended solids

Upflow anaerobic sludge bed

Volatile fatty acid

${ }^{1}$ Corresponding author's present address: Department of Civil Engineering, State University of Ponta Grossa, Av. General Carlos Cavalcanti 4748, Ponta Grossa, Paraná 84030-900, Brasil. 


\begin{abstract}
Recirculation of treated effluent is usually used to prevent organic overloading events in anaerobic digestion of high concentrated wastewater. The aim of this study was to determine the influence of effluent recirculation in anaerobic baffled reactors (ABR) treating high concentrated wastewater as the literature is not conclusive about its effects. To achieve this, an innovative experimental and mathematical modeling dual approach was used. A benchscale ABR was fed with sugarcane vinasse $\left(\mathrm{COD}=18.0 \mathrm{~g} \mathrm{~L}^{-1}\right)$ and monitored for 273 days. Real kinetic and mass transfer parameters were obtained and used to create a mathematical model for the organic matter conversion. Operating data and the kinetic parameters showed that at high COD concentrations the ABR does not behave as a two-stage system as expected. Both results, i.e. the mathematical model and the operational data, showed that in terms of conversion capacity using high recirculation ratios is not necessary for suitable ABR performances, only increasing operational costs due to pumping.
\end{abstract}

Keywords: sugarcane vinasse, anaerobic process modelling, effective diffusivity, substrate inhibition. 


\section{INTRODUCTION}

Vinasse management requires careful planning to control the environmental impact of sugarcane-based ethanol biorefineries. Currently, fertirrigation is virtually the only approach used in the Brazilian sucro-alcohol sector. Fertirrigation, i.e., the direct land application of vinasse into sugarcane fields, aims to recycle nutrients and water to crops [1]. Despite some beneficial aspects, the continuous and long-term land application of vinasse, which is often associated to a lack of proper technical criteria, tends to reduce the productive capacity of soils, crop yields and even the quality of the water bodies [2]. Bioenergy losses due to the uncontrolled conversion of organic matter by soil microbial populations also result from the land disposal of vinasse.

Anaerobic digestion (AD) is a suitable option for the management of vinasse to minimize/eliminate negative effects from fertirrigation, simultaneously reducing the polluting potential of the wastewater and recovering bioenergy through biogas production $[2,3]$. Different reactor configurations have been used to process sugarcane vinasse, such as: fixedfilm [4], fluidized-bed [5,6], sludge blanket [7,8], sequencing batch [9] and hybrid reactors $[10,11]$, which combine the advantages of both fixed- and sludge-bed systems. However, most of the reports are limited to demonstration scale experiments.

Despite the successful results usually reported when treating sugarcane vinasse with anaerobic systems [12], additional studies are still required to enhance treatment performance, including defining both suitable reactor configurations and operating strategies. In terms of reactor configurations, the anaerobic baffled reactor (ABR), which was inspired by the baffled reactor, is highlighted in this study. The main advantage of this particular configuration is the ability to separate acidogenesis from methanogenesis throughout the reactor, potentially allowing the system to behave as a two-stage process [13]. The operation with phase separation tends to simultaneously enhance both the acidogenic and methanogenic activities, as acidogenic bacteria are accumulated in the first baffle $[14,15]$ and different groups of syntrophic bacteria and archaea can grow in the subsequent baffles.

With respect to the operating conditions, some aspects must be carefully considered, such as the provision of enough alkalinity to ensure an adequate buffering capacity [16] and the control of the organic loading applied to the digesters. The high concentration of organic matter found in vinasse tends to inhibit some bioconversion reactions, especially the ones carried out by methanogens, enhancing the accumulation of volatile acids, and potentially leading digesters to collapse. Thus, specific operating strategies are required to prevent organic overloading in anaerobic reactors treating vinasse, therefore the recirculation of the treated effluent may be a feasible option $[17,18,19]$. This strategy brings benefits to the 
control of both buffering capacity and organic loading, as the bicarbonate resulting from acetate conversion is recycled to neutralize the high acidity of the raw vinasse with a simultaneous dilution of the high organic fractions fed into the system.

In the particular case of the ABR, recirculation may negatively impact treatment performance as the reactor tends to become a completely stirred system [20], so that the benefits from phase separation are partially lost [21]. Intense mixing conditions also increase solid losses, break microstructures of microorganisms arranged in symbiotic relationships [22], as well as increase the amount of dead spaces within digesters [23,24]. Bachmann et al. [25] reported that the methanogenic activity was more evenly distributed throughout an ABR after introducing recirculation, whereas Nachaiyasit [24] observed a decrease in gas production in the reactor when the rate of recirculation was increased. On the other hand, positive effects, such as higher methane production rates [26] and a more efficient $\mathrm{pH}$ control [27] could be associated to the implementation of recirculation in AD systems. Additional benefits from effluent recirculation include the dilution of toxic compounds and the reduction of inhibitory effects from high substrate concentrations [28].

Overall, previous studies indicate that the benefits of recycling in baffled reactors are uncertain, and its application as an operating strategy depends on the type of wastewater to be treated. When potential limitations associated to fast acidification and high organic loadings are considered, such as in the case of vinasse, recirculation should be beneficial. However, the drawbacks inherent to recirculation show that such an approach should be carefully considered and only used when absolutely necessary. In this context, this study aimed to determine the influence of effluent recirculation in an ABR treating high concentrated sugarcane vinasse, as the literature is not conclusive about its effects. For this purpose, an experimental and mathematical modeling dual approach was used. To the best of our knowledge, this is the first study presenting both the application of the ABR to the treatment of sugarcane vinasse and the modelling of the degradation kinetics of vinasse in heterogeneous AD systems.

\section{EXPERIMENTAL APPROACH}

\subsection{ABR monitoring: reactor configuration, substrate characterization and operating conditions}

A bench-scale ABR consisting of four baffles, namely B1, B2, B3 and B4, was built in PVC. The basic layout of the treatment system is depicted in Figure 1. Each baffle was 800 $\mathrm{mm}$ high, with an outlet port at $640 \mathrm{~mm}$, connected with the bottom of the next baffle with a 
$32 \mathrm{~mm}$ diameter tube. The diameter of each baffle was $100 \mathrm{~mm}$, leading to individual reaction volumes of $5 \mathrm{~L}$ and a total volume of $20 \mathrm{~L}$. The ABR was inoculated with granular sludge at a concentration of $50 \mathrm{~g}-\mathrm{VSS} \mathrm{L}^{-1}$. The inoculum was collected from a full-scale UASB reactor treating poultry wastewater. The reactor was then filled with tap water up to the operating volume and the initial residence time was set to 40 days (OLR $\left.=0.5 \mathrm{~g}-\mathrm{COD} \mathrm{L}^{-1} \mathrm{~d}^{-1}\right)$, without effluent recirculation.

[Figure 1 near here]

A peristaltic pump was used to feed the ABR, so that the sugarcane vinasse $(18.0 \pm 1.4$ g-COD L ${ }^{-1}$ and $1.5 \pm 0.8 \mathrm{~g}-S S ~ L^{-1}$ ) was continuously fed to the system for 273 days under mesophilic temperature conditions. Increasing organic loading rates (OLRs, up to approximately 2.0 g-COD L-1 $\mathrm{d}^{-1}$ ) were applied in the ABR by increasing the feed flow rate. The $\mathrm{pH}$ of vinasse was adjusted by adding sodium bicarbonate $\left(\mathrm{NaHCO}_{3}\right)$ at a ratio of $0.5 \mathrm{~g}$ $\mathrm{HCO}_{3} \mathrm{~g}^{-1} \mathrm{COD}$, also aiming to control the buffer capacity of the system and prevent the accumulation of volatile fatty acids (VFA). External nutrient supplementation was not provided as vinasse naturally contains appreciable concentrations of macro- and micronutrients [2]. In particular, total Kjeldahl nitrogen and phosphate concentrations in the vinasse used as substrate were respectively $345 \mathrm{mg} \mathrm{L}^{-1}$ and $102 \mathrm{mg} \mathrm{L}^{-1}$ [7], performing a COD:N:P relation of approximately 176.5:3.4:1.0.

\subsubsection{Performance assessment and analytical methods}

The performance of the ABR was assessed by monitoring $\mathrm{COD}$ conversion, $\mathrm{pH}$, suspended solid (SS) concentration, partial (PA) and intermediate (IA) alkalinity and volatile fatty acids (VFA) for the influent (raw vinasse) and effluent of each baffle. COD, $\mathrm{pH}$ and SS measurements were performed according to the protocols described in the Standard Methods for the Examination of Water and Wastewater [29]. The PA (alkalinity due to the presence of bicarbonate ions) and IA (alkalinity due to the presence of ionic volatile organic acids) measurements were based on the procedures described by Ripley et al. [30], whereas VFA were determined according to DiLallo and Albertson [31].

At the end of the operating period, the sludge was taken from each baffle and the granule diameter was measured according to the method proposed by Alves et al. [32]. Measurements consisted of taking $10 \mathrm{~mL}$ of sludge samples, separating the granules from particulate materials by sedimentation, capturing images of the granules, and measuring their dimensions computationally. Images were captured by a digital scanner (Model Scanjet 3770, 
Hewlett-Packard Company, Palo Alto, California, USA) and analyzed using the software Image-Pro Plus 6.0 (Media Cybernetics Inc., Rockville, Maryland, USA).

\subsection{Kinetic assays: determining reactor design parameters}

Kinetic parameters were obtained to be used later in the mathematical model of the system, including the diffusivity of vinasse into the granules and the kinetic parameters of substrate consumption. Determinations were carried out in batch tests using a shaker (Model 430/RDBP, Nova Ética, Vargem Grande Paulista, SP, Brazil) at mesophilic temperature conditions $\left(25^{\circ} \mathrm{C}\right)$. The determination of the minimum rotation speed of the shaker $\left(R_{\min }\right)$ to eliminate external mass transfer resistance preceded the diffusivity and kinetic assays.

\subsubsection{Minimum rotation speed $\left(R_{\text {min }}\right)$}

Preliminary kinetic assays were carried out in $500 \mathrm{~mL}$ Duran ${ }^{\circledR}$ flasks at different rotation speeds, i.e., 50, 150, 200, and $250 \mathrm{rpm}$. Granular biomass adapted to the treatment of sugarcane vinasse was used as the inoculum. The organic matter concentration of vinasse (as COD) was about $15 \mathrm{~g} \mathrm{~L}^{-1}$. The flasks were filled with $300 \mathrm{~mL}$ of substrate and $1.5 \mathrm{~g}$ of granular sludge. $\mathrm{NaHCO}_{3}$ was added in order to provide appropriate alkalinity levels to the reactors [33]. Nitrogen was flushed for 10 minutes into the flasks to ensure anaerobic conditions within the reactors. Samples were collected at different times and COD measurements were performed. The initial reaction rates $\left(r_{0}\right)$ were obtained for each rotation speed applied to the shaker through mathematical adjustments (COD vs time).

\subsubsection{Substrate diffusivity in anaerobic granules}

Methanogenic granules taken from the full-scale UASB reactor treating poultry wastewater (ABR inoculum) were washed in tap water, sieved and inactivated in a $50 \%(\mathrm{v} / \mathrm{v})$ ethanol solution for 2 hours [34]. The inactivation aimed to prevent biochemical reactions during the experiment. The granules were then washed in distilled water up to the absence of apparent color in the wash water. This step aimed to eliminate the interference of ethanol in COD measurements.

Batch tests were also performed in $500 \mathrm{~mL}$ Duran ${ }^{\circledR}$ flasks using sugarcane vinasse $\left(\mathrm{COD}=15 \mathrm{~g} \mathrm{~L}^{-1}\right)$ as the substrate. The flasks were filled with $50 \mathrm{~mL}$ of vinasse and $10 \mathrm{~g}$ of granular sludge. Granule diameter was measured according to the method proposed by Alves et al [32]. Each flask was sampled at a given time during the incubation period, and then the content of the flask was discarded. Vinasse samples were promptly filtered $(0.45 \mu \mathrm{m})$ to prevent the contact of the substrate with the granular sludge and were then analyzed for COD. 
The experiments were carried out in duplicate, and samples were collected at different instants between 0 and 10 minutes. Temporal profiles for substrate concentration under negligible external mass transfer resistance and in the absence of biochemical reactions for substrate utilization were obtained, and then used to calculate the effective diffusivity of vinasse in the UASB granules.

\subsubsection{Substrate consumption rates}

Kinetic assays for substrate consumption followed the methodology presented by Vieira et al. [35], which allows the estimation of the intrinsic kinetic parameters, i.e., the reaction rates of immobilized cells without considering limitations to mass transfer. This method is based on the determination of the kinetic parameters in the absence of external resistance to mass transfer through sufficient mixing to eliminate the stagnated liquid film surrounding the granules or bioparticles. This method is valid when the Thiele observed modulus $\left(\varphi_{o b s}\right)$ is lower than 0.3 [35] (Equation 1). In Equation $1 r_{o b s}$ is the observed substrate consumption rate, $C_{S}$ is the substrate concentration (COD), $V_{p}$ and $A_{p}$ are the volume and surface area of the granule, respectively. $V_{p}$ and $A_{p}$ values were obtained from the diameter of the granules experimentally measured [32] (Section 2.2).

$$
\varphi_{\text {obs }}=\frac{\mathrm{r}_{\mathrm{obs}}}{\mathrm{D}_{\mathrm{e}} \cdot \mathrm{C}_{\mathrm{S}}}\left(\frac{\mathrm{V}_{\mathrm{p}}}{\mathrm{A}_{\mathrm{p}}}\right)^{2}
$$

Granular sludge taken from each baffle and vinasse sample with approximately $15 \mathrm{~g} \mathrm{~L}^{-}$ ${ }^{1}$ of COD were used in assays carried out in triplicate. Temperature conditions and alkalinity provision followed the same protocol described in Section 2.2.2. Biomass concentrations within the flasks were about $0.005 \mathrm{~g}$-VSS L-1.

\section{MODELLING APPROACH}

\subsection{Substrate diffusivity}

The mass balance of non-steady state diffusion processes in spheres, as is approximately the case for UASB granules, and accounting for radial diffusion only, can be expressed by Equation (2) [36], where $C_{S}$ is the concentration of substrate (COD), $t$ is the time, $D_{e}$ is the effective diffusivity, and $r_{p}$ is the radius of the sphere. Crank [37] derived a range of solutions for Equation (2), so that for diffusion in a well-stirred vessel of limited 
volume, the total amount of solute that diffuses into the sphere after time $\mathrm{t}\left(M_{t}\right)$ is expressed as a fraction of the corresponding quantity after infinite time $\left(M_{\infty}\right)$, according to Equation 3 . The terms $\alpha$ and $M_{\infty}$ are respectively the ratio between the volumes of the solution and of the sphere and the amount of mass diffused into the granule at equilibrium. In turn, $q_{n}$ is the nonzero root of Equation (4).

$$
\begin{aligned}
& \frac{\partial \mathrm{C}_{\mathrm{S}}}{\partial \mathrm{t}}=\mathrm{D}_{\mathrm{e}}\left(\frac{\partial^{2} \mathrm{C}_{\mathrm{S}}}{\partial \mathrm{r}_{\mathrm{p}}{ }^{2}}+\frac{2 \partial \mathrm{C}_{\mathrm{S}}}{\mathrm{r}_{\mathrm{p}} \partial \mathrm{r}_{\mathrm{p}}}\right) \\
& \frac{\mathrm{M}_{\mathrm{t}}}{\mathrm{M}_{\infty}}=1-\sum_{\mathrm{n}=1}^{\infty} \frac{6 \alpha(\alpha+1) \exp \left(-\mathrm{De} \cdot \mathrm{q}_{\mathrm{n}}^{2} \cdot \mathrm{t} / \mathrm{r}_{\mathrm{p}}{ }^{2}\right)}{9+9 \alpha+\mathrm{q}_{\mathrm{n}}^{2} \alpha^{2}} \\
& \mathrm{q}_{\mathrm{n}}=\operatorname{arctg} \frac{3 \mathrm{q}_{\mathrm{n}}}{3+\alpha \mathrm{q}_{\mathrm{n}}^{2}}
\end{aligned}
$$

The approach developed by Crank [37] does not take into account the flow into the sphere pores, but only the diffusion in a particle with spherical shape. As the void fraction in UASB granules is high, the diffusion inside them was conservatively considered as the diffusion into a sphere of the same diameter. By using the experimental profile of the substrate concentration, and according to the procedure described in Section 2.2.2, the diffusion parameter value which minimizes the square error between the left- and right-hand side of Equation (3) was obtained.

\subsection{Kinetic parameters}

Polynomial functions relating substrate concentration vs. time were adjusted to the temporal profiles of substrate consumption obtained according to the methodology described in Section 2.2.3. Derivatives of these polynomials at different times represented the reaction rate. In order to obtain the intrinsic kinetic parameters, the reaction rates were evaluated according to different kinetic models: first- and second-order decay (Equations 5 and 6), firstand second-order decay with residual (Equations 7 and 8), Monod kinetics [38] (Equation 9), and kinetics with inhibition by substrate excess (Equation 10), which is an analogy to the enzymatic kinetic model proposed by Andrews [39]. In Equations (5)-(10) the terms $r, k, C_{S}$, $C_{\text {res }}, r_{\text {max }}, K_{S}$ and $K_{i}$ are, respectively, the reaction rate, the kinetic constant, the substrate 
concentration, the residual substrate concentration, the maximum reaction rate, the saturation constant and the inhibition constant.

$$
\begin{gathered}
\mathrm{r}=\mathrm{k} \cdot \mathrm{C}_{\mathrm{S}} \\
\mathrm{r}=\mathrm{k} \cdot \mathrm{C}_{\mathrm{S}}{ }^{2} \\
\mathrm{r}=\mathrm{C}_{\mathrm{res}}+\mathrm{k} \cdot \mathrm{C}_{\mathrm{S}} \\
\mathrm{r}=\mathrm{r}_{\mathrm{max}} \frac{\mathrm{C}_{\mathrm{S}}+\mathrm{k} \cdot \mathrm{C}_{\mathrm{S}}{ }^{2}}{\mathrm{C}_{\mathrm{S}}} \\
\mathrm{r}=\mathrm{r}_{\max } \frac{\mathrm{C}_{\mathrm{S}}}{\mathrm{C}_{\mathrm{S}}+\mathrm{K}_{\mathrm{S}}+\frac{\mathrm{C}_{\mathrm{S}}{ }^{2}}{\mathrm{~K}_{\mathrm{i}}}}
\end{gathered}
$$

\subsection{ABR modelling}

Using the kinetic and mass transfer parameters obtained according to Sections 2.2.2, 2.2.3, 3.1 and 3.2, a model of four heterogeneous completely stirred tank reactors (CSTR) in series with recirculation and at steady state conditions (Figure 2) was implemented in Matlab ${ }^{\circledR}$ (The MathWorks, Inc., Natick, Massachusetts, USA) to describe the COD profiles throughout the reactor. COD represents the oxygen demand widely used to indirectly quantify the concentration of organic matter in a given source. Although a "concentration of COD", i.e., the concentration of a demand, cannot be physically expressed, for modelling purposes the COD was considered a substrate in this study and, therefore, $C_{C O D}$ represents the substrate concentration in the model.

[Figure 2 near here]

Reactors containing sludge blankets, such as UASB systems and each baffle in the $\mathrm{ABR}$, can be modeled as combinations of completely stirred and plug-flow reactors. However, Wu and Hickey [40] reported that more than $90 \%$ of the volume of sludge blanket 
systems may be represented as a CSTR, mainly due to the mixing conditions provided by the generation of biogas. Given that the primary target of this study was to verify the capacity of the $\mathrm{ABR}$ in converting organic matter and not its solids retention capacity (plug-flow region of the reactor), each baffle was modeled as a CSTR.

The mass balance for each baffle was obtained according to Equation (11), where $\tau$ is the residence time, $C_{C O D, i}$ is the COD in the effluent of baffle $i, C_{C O D, i-1}$ is the COD in the influent of baffle $i$ (effluent from baffle $i-1$ ), and $r$ is the reaction rate. By introducing a recirculation stream, the reactor feed concentration changes as a function of the overall efficiency of the system. Thus, it was necessary to include Equation (12) into the model, which calculates $C_{C O D, m i x}$, i.e., the concentration of the influent mixture applied to the reactor. In Equation (12) $R e c$ is the recirculation ratio, $C_{C O D, B 4}$ is the COD in the effluent of $\mathrm{B} 4$ and $C_{C O D, F}$ is the COD of raw vinasse in the feeding stream.

$$
\begin{gathered}
\tau=\frac{\mathrm{C}_{\mathrm{COD}, \mathrm{i}}-\mathrm{C}_{\mathrm{COD}, \mathrm{i}-1}}{\mathrm{r}} \\
\mathrm{C}_{\mathrm{COD}, \text { mix }}=\frac{\operatorname{Rec} \cdot \mathrm{C}_{\mathrm{COD}, \mathrm{B} 4}+\mathrm{C}_{\mathrm{COD}, \mathrm{F}}}{\operatorname{Rec}+1}
\end{gathered}
$$

In heterogeneous reactors, mass transfer limitation effects can be considered as intrinsic kinetic deviations. External mass transfer was assessed by the external mass transfer coefficient $\left(k_{m} a\right)$ (Equation 13) and its relationship with the intrinsic kinetic parameters, where the terms $S h, d_{p}, D_{s, l}$ are, respectively, the Sherwood number, the diameter of the particle and the diffusivity of substrate in the liquid phase. In this case, the diffusivity of acetic acid in water $\left(D_{s, l}=2.35 \times 10^{-5} \mathrm{~cm}^{2} \mathrm{~s}^{-1}\right)$ was used, considering that this is the primary substrate of interest in anaerobic digestion. According to Schmidt [41], Sh equals 8/3 for liquid flows with a Reynolds number $(R e)$ lower than 2100 . Once $k_{m} a$ was determined, $k_{e f f}$, which refers to the intrinsic kinetic parameter with a correction due to external mass transfer limiting effects, was obtained according to Equation (14).

$$
\begin{aligned}
\mathrm{k}_{\mathrm{m}} \mathrm{a} & =\frac{\mathrm{Sh} \cdot \mathrm{D}_{\mathrm{S}, \mathrm{l}}}{\mathrm{d}_{\mathrm{p}}} \\
\mathrm{k}_{\mathrm{eff}} & =\frac{\mathrm{k}}{1+\mathrm{k} / \mathrm{k}_{\mathrm{m}} \mathrm{a}}
\end{aligned}
$$


Finally, studying heterogeneous reactors also requires analyzing internal mass transfer resistance effects. Therefore, the effective coefficient $\left(E_{f f}\right)$ was estimated, which represents the deviation of the intrinsic kinetic parameters due to internal mass transfer resistance. For irreversible first-order kinetics, Equation (15) may be used to determine $E_{f f}$ in spheres [42]. The term $\varphi$ (Thiele modulus) was calculated according to Equation (16), whereas the terms $d_{p}$, $D_{e}$ and $k$ were previously obtained according to the methods presented in Sections 2.1.1, 2.2, 3.1 and 3.2 .

$$
\begin{aligned}
& \mathrm{E}_{\mathrm{ff}}=\frac{1}{\varphi} \cdot\left(\frac{1}{\tanh (3 \varphi)}-\frac{1}{3 \varphi}\right) \\
& \varphi=\frac{\mathrm{dp}}{12} \sqrt{\frac{\mathrm{k}}{\mathrm{De}}}
\end{aligned}
$$

\section{RESULTS AND DISCUSSION}

\subsection{Overall ABR performance}

The suitability of treating sugarcane vinasse in anaerobic baffled reactors was assessed in a continuous bench-scale system monitored for 273 days (39 weeks). Overall data regarding the applied OLR, COD concentrations IA/PA ratio values and VFA concentrations are depicted in Figures 3a-d. Details of each baffle (B1-B4) and the overall performance are considered. Throughout the entire operating period, even during VFA buildup events, the $\mathrm{pH}$ measured in all baffles reached values higher than 6.5, which corresponds approximately to the lower $\mathrm{pH}$ at which adequate conditions are provided to methanogens [43]. COD removal efficiency reached levels above $90 \%$ over $95 \%$ of the operating period, regardless of the applied OLR. The observed values are equivalent-to-higher compared to different bench-scale anaerobic systems used to treat sugarcane vinasse, such as sludge blanket $(87.5 \%$, OLR $=$ 0.5-32.4 g-COD L-1 $\mathrm{d}^{-1}[7] ; 63.0 \%$, OLR $=25 \mathrm{~g}-\mathrm{COD} \mathrm{L}^{-1} \mathrm{~d}^{-1}[8] ; 62.9 \%$, OLR $=25 \mathrm{~g}-\mathrm{COD} \mathrm{L}^{-}$ $\left.{ }^{1} \mathrm{~d}^{-1}[44]\right)$ and fixed-film reactors $\left(73.0-82.0 \%\right.$, OLR $=15 \mathrm{~g}-\mathrm{COD} \mathrm{L}^{-1} \mathrm{~d}^{-1}[4] ; 73.2 \%, \mathrm{OLR}=$ $30 \mathrm{~g}-C O D ~ L^{-1} \mathrm{~d}^{-1}$ [44]. However, the maximum applied OLR in the ABR $\left(\sim 2 \mathrm{gCOD} \mathrm{L}^{-1} \mathrm{~d}^{-1}\right.$; Figure 3a) was much lower relative to the comparative systems, potentially indicating operating limitations of the assessed reactor configuration in the treatment of this particular wastewater.

[Figure 3 near here] 
High solid concentrations characterize one of the main limiting aspects that impact the anaerobic conversion of vinasse, so that high residence times are required in digesters to enhance the hydrolysis step. In this study, SS concentrations in the influent and effluent streams from the ABR reached $1.5 \pm 0.8 \mathrm{~g} \mathrm{~L}^{-1}$ and $0.6 \pm 0.6 \mathrm{~g} \mathrm{~L}^{-1}$, respectively, indicating a solid retention capacity of approximately $60 \%$ in average terms. Effluent SS concentrations reported for sludge blanket and fixed-film systems also treating sugarcane vinasse were 2.5fold higher [44] compared to the values observed in the ABR. This feature may be explained by the low upflow velocity in each baffle, as well as by the arrangement as a series of digesters which also favored such a condition. In particular, such results may explain the high COD removal levels in the ABR, regardless of the operating condition.

Regarding the generation of alkalinity and acidity, Figure $3 \mathrm{c}$ indicates values lower than 0.3 for the IA/PA ratio during about $73 \%$ of the operating period in baffles B2, B3 and B4, suggesting balanced conditions in the production and consumption of VFA [30]. The IA/PA ratio roughly relates the amounts of VFA and bicarbonate alkalinity in anaerobic reactors, measuring the buffer potential of the systems. IA/PA ratio values lower than 0.3 indicate a bicarbonate concentration at least three-fold lower compared to VFA, most likely indicating the operation of baffles B2 to B4 under approximate steady-state conditions. In turn, the IA/PA ratio in B1 was usually higher than 0.3 , i.e., with values above 0.5 and peaking at 1.0-1.2 (Figure 3c), which could be attributed to the higher OLR applied (compared to baffles B2 to B4) and also to the variations on the raw vinasse. The application of high OLRs favor the activity of fermentative microbial populations, whose doubling times are much higher (30 minutes to a few hours) compared to methanogens (a few hours to 2-3 days) [45], promoting the accumulation of VFA and, therefore, providing unfavorable conditions to the methanogenic activity. Given that aceticlastic methanogenesis provides bicarbonate alkalinity in loco to anaerobic reactors (Reaction 1) [46], impairing this particular archaeal population directly impacts the IA/PA ratio by decreasing PA values.

$$
\mathrm{CH}_{3} \mathrm{COO}^{-}+\mathrm{H}_{2} \mathrm{O} \rightarrow \mathrm{HCO}_{3}^{-}+\mathrm{CH}_{4}
$$

Episodes of VFA accumulation in B1 and B2 were observed three times, indicating values of 4180, 3643 and $3284 \mathrm{mg} \mathrm{L}^{-1}$ (B1) and 2624, 2405 and $1626 \mathrm{mg} \mathrm{L}^{-1}$ (B2) approximately at weeks 10, 19 and 22, respectively (Figure 3d). In particular, this pattern most likely resulted from the continuous increase in the applied OLR (Figure 3a), suggesting that values of approximately $2 \mathrm{~g}-\mathrm{COD} \mathrm{L}^{-1} \mathrm{~d}^{-1}$ are limiting to vinasse-fed ABRs. VFA 
accumulation in B3 and B4 was evident only in the first event (week 10), whereas VFA concentrations remained approximately stable in the terminal baffles during the second and third acidification events (weeks 19 and 22, respectively). Such discrepant behavior most likely resulted from the adaptation of the anaerobic sludge to the sugarcane vinasse and operating conditions throughout the experiment. The temporal profiles obtained for the COD removal efficiency (Figure 3b) presented a similar pattern to the ones observed for VFA concentrations (Figure 3d), with minimal variations in the COD levels in B3 and B4 during the second and third events of reactor acidification (weeks 19 and 22, respectively). This result corroborates the hypothesis of biomass adaptation, also indicating the robustness of the ABR towards the accumulation of VFA in the first baffles. COD removal levels observed in this study indicated that baffles B2 to B4 acted as a polishing system for the effluent stream from B1.

The results obtained indicate that the ABR did not behave as a two-stage anaerobic system when applied to the treatment of high-strength wastewaters, such as sugarcane vinasse, in the assessed conditions. The accumulation of volatile acids due to wastewater characteristics and increasing OLR conditions did not allow a differentiation in the function of the baffles throughout the reactor. Applying operating modifications, such as the provision of bicarbonate alkalinity from the second baffle onwards, could lead to a more effective differentiation of the anaerobic process throughout the ABR. In this case, the enhanced accumulation of VFA without external dosing of alkalizing agents would most likely suppress the methanogenic activity in B1, whereas a more effective organic matter removal would be only observed in baffles B2-B4.

The ratio between the COD and BOD values in the last week of operation Error!

Reference source not found.(Table 1) indicated the presence of high levels of hard-todegrade organic matter in the effluents from B1 onwards. For a given effluent, COD/BOD ratio values lower than 2.5 indicate high levels of biodegradable organic compounds, whereas for values above 4.0 the non-biodegradable fraction is high, and the application of biological treatment processes may be considered unsuitable [47]. Thus, increasing the residence time would not result in efficiency gains, as the COD/BOD ratio measured in the effluent from B1 reached a value above 5 (Table 1). Additional technologies could be used as subsequent steps to the ABR to enhance treatment performance, such as using membranes or physicochemical processes. However, additional technologies would require higher investment and operating costs. The remaining organic fraction most likely consisted of phenols and melanoidins, characterized as the primary recalcitrant compounds found in vinasse [48,49]. Melanoidins are colorant compounds resulting from the Maillard reaction between sugars and proteins at 
high temperatures [48], and its presence in vinasse is strictly associated with using molasses in ethanol fermentation. In turn, phenolic compounds result from the hydrolysis of remaining lignocellulosic structures throughout sugarcane processing [50], including the first steps of the anaerobic conversion of the organic matter.

[Table 1 near here]

\subsection{Kinetic assessment: minimum rotation speed, substrate diffusivity and reactor parameters}

The minimum rotation speed was defined prior to the assessment of both substrate diffusivity and the kinetic parameters for the consumption of organic matter. The initial reaction rates obtained for the different rotation speeds assessed are depicted in Figure 4a, according to the methods detailed in Section 2.2.1. The results indicated that for rotation speeds above $200 \mathrm{rpm}$ the resistance to external mass transfer could be considered negligible, as the rate of substrate consumption remained constant. The final $\mathrm{pH}$ was above 6.6 in all monitored flasks, indicating the establishment of favorable conditions for methanogens [43].

[Figure 4 near here]

The results further obtained in diffusivity assays (Section 2.2.2) are presented in Figure $4 \mathrm{~b}$. Although experiments were carried out for incubation periods of up to 10 minutes, vinasse diffusion into the granules occurred essentially in the first 60 seconds. The $C_{C O D}$ decay was fitted with Equation (17). By solving Equation 17 at different times, it was possible to determine the values for $M t / M \infty$ required to calculate De in Equation (3). By combining Equations (3), (4) and (17), and using the granule average diameter obtained experimentally $(1.74 \pm 0.32 \mathrm{~mm}$; Supplementary material), the effective diffusion of COD into the UASB granules was estimated as $1.26 \pm 0.20 \times 10^{-5} \mathrm{~cm}^{2} \mathrm{~s}^{-1}$, which is similar to the values obtained by Vela et al. [34] for different substrates, i.e. glucose, sucrose and acetate (Table 2). Such correspondence of values probably results from the compositional aspects of vinasse, which are characterized by high levels of residual carbohydrates and organic acids.

$$
\mathrm{C}_{\mathrm{COD}}=13961.51+1060.65 \cdot \exp \left(\frac{-\mathrm{t}}{17.58}\right)
$$


[Table 2 near here]

Regarding the estimation of substrate consumption rates, the values estimated for the saturation constant $\left(K_{S}\right)$ when assessing microbiological kinetic models exceeded the initial concentration of substrate in baffles B2 to B4. According to the Monod model [38] (Equation 9), $K_{S}$ indicates half of the substrate concentration from which increases in concentration do not result in increases on the degradation rate, i.e., a zero-order reaction is observed. Since $K_{S}$ was higher than the initial concentrations, the first-order model with residual was used for baffles B2 to B4 (Equation 7). Table 3 compiles the kinetic parameters obtained from the mathematical fitting based on the presence of hard-to-degrade organic matter fractions in vinasse. Aquino et al. [4] and Kiyuna et al. [51] also fitted a first-order model with residual concentration to COD decays in sugarcane vinasse-fed fixed-film reactors and batch reactors, respectively, which is consistent with the pattern observed herein and confirms the recalcitrance of biodigested vinasse.

[Table 3 near here]

In the case of baffle B1, kinetic data showed a better adjustment to the model of inhibition by substrate excess (Equation 10). The residual term obtained for baffle B4 was used in the baffle B1 kinetic model, as microbiological models do not allow the determination of residual terms directly. However, reactor operating data indicated that the nonbiodegradable organic matter residual concentration was lower than that obtained in the kinetic assays $\left(C_{C O D}\right.$ lower than $\left.2.36 \mathrm{~g} \mathrm{~L}^{-1}\right)$. Since $r_{o b s}$ (maximum observed substrate consumption rate) $=9.12 \mathrm{mg}^{-} \mathrm{COD} \mathrm{\textrm {mg } ^ { - 1 }} \mathrm{VSS} \mathrm{h}^{-1}, \mathrm{VSS}=5.0 \mathrm{mg} \mathrm{L}{ }^{-1}, D_{e}=1.26 \cdot 10^{-5} \mathrm{~cm}^{2} \mathrm{~s}^{-1}$, $C_{S}=10310 \mathrm{mg}-\mathrm{COD} \mathrm{L}^{-1}$ (concentration related to the maximum observed substrate consumption rate) and $d_{p}=1.89 \mathrm{~mm}$ (diameter in which the maximum reaction rate is observed), the observed Thiele modulus could be calculated using Equation (1), from a value of $9.7 \times 10^{-7}$ was obtained. Considering that the kinetic assays resulted in $\varphi_{o b s}<<0.3$, the method used to obtain the parameters was considered adequate.

The analysis of the kinetic parameters showed that the baffles behaved similarly, with no significant difference in terms of COD removal potential. The first-order kinetics obtained for baffles B2 to B4 presented few differences compared to the first-order kinetic stretch in B1. Therefore, new sets of kinetic parameters were determined, assuming that the baffles had the same substrate degradation capacity. Figure 5 presents the reaction rates obtained in the tests for B1, B2, B3 and B4, as well as adjustments to combinations of data sets: B1, B1+B2, 
$\mathrm{B} 1+\mathrm{B} 2+\mathrm{B} 3$ and $\mathrm{B} 1+\mathrm{B} 2+\mathrm{B} 3+\mathrm{B} 4$. It can be concluded in Figure 5 that the kinetic models differ little among the combinations considered for the baffles. Therefore, it is reasonable to assume that the whole reactor follows the same kinetic model. For inhibition kinetics by substrate excess (Equation 10), the results were: $r_{\max }=9.57 \mathrm{mg}-\mathrm{COD} \mathrm{L}^{-1} \mathrm{~d}^{-1} \mathrm{mg}^{-1} \mathrm{VSS}, K_{S}=17141 \mathrm{mg}$ $\mathrm{COD} \mathrm{L}^{-1}$ and $K_{i}=9985 \mathrm{mg}-\mathrm{COD} \mathrm{L}^{-1}$.However, reductions on the substrate consumption rate may be considered slight for COD values within the range of 15 to $20 \mathrm{~g} \mathrm{~L}^{-1}$.

In practical aspects, any recirculation rate may be applied to the system without hindering the treatment capacity of the reactor in kinetic terms (losing characteristics of twophase separation). Given that all baffles follow the same kinetic model, the ABR already behaves as a single-stage digester and, therefore, effluent recirculation will not have any influence over it. Nevertheless, when the reactor behaves as a CSTR the advantages associated to plug-flow reactors are not observed.

\subsection{ABR modelling}

Although the models obtained for the ABR were not expected to follow first-order kinetics, but microbiological kinetics instead, they were evaluated in the mathematical model of the reactor as analogous to first-order kinetics (Equation 7), given that most of the operating points assessed were in the first-order region of the microbial kinetic model. Equations (14) and (15) were used to determine the corrections due to mass transfer limitations. Equation (18) indicates the simplifications considered for the microbiological kinetic models, so that $\mathrm{C}_{\mathrm{S}}{ }^{*}$ replaces the $\mathrm{C}_{\mathrm{S}} /\left(\mathrm{C}_{\mathrm{S}}+\mathrm{K}_{\mathrm{S}}\right)$ or $\mathrm{C}_{\mathrm{S}} /\left(\mathrm{C}_{\mathrm{S}}+\mathrm{K}_{\mathrm{S}}+\mathrm{C}_{\mathrm{S}}{ }^{2} / \mathrm{K}_{\mathrm{i}}\right)$ terms, depending on the model. Figure 6 compares COD removal data obtained both experimentally and mathematically. Although the correlation is limited, the same decreasing trend may be observed for both curves in each baffle.

$$
\mathrm{r}=\mathrm{r}_{\max } \cdot \mathrm{C}_{\mathrm{S}}^{*}
$$

The overall efficiency of the reactor suggested by the model for a fully anaerobically degradable wastewater for different recirculation ratios and residence times $(\tau)$ is presented in Figure 7a. For recirculation ratios above 1.0-2.0, no significant gains are associated with the treatment capacity of the ABR. Furthermore, for a given recirculation ratio no relevant improvements were observed in the overall treatment performance for residence times longer than 6 days (Figure 7a), which seems to be the maximum treatment capacity of the reactor. For residence times longer than 8 days, the presence of recirculation is virtually irrelevant. In particular, Figure $8 \mathrm{~b}$ shows COD removal efficiency values specifically for the first baffle of 
the reactor according to the model, considering different recirculation ratios. Results indicate that increasing the recirculation ratio up to 2.0 is beneficial for the organic matter conversion in baffle B1. In addition to mitigating the acid loadings inherent in reactor operation with high OLR, the first baffle would operate in more favorable kinetic points, less susceptible to the limitation by substrate excess. For residence times over 10 days, recirculation has little relevance.

\section{CONCLUSIONS}

The ABR behaved as a single-stage system and recirculation did not result in relevant performance improvements. In particular, the single-stage behavior was confirmed by similar sets of kinetic parameters obtained for all baffles. Strong inhibition by substrate excess is the prerogative for applying effluent recirculation vinasse biodigestion. However, since the observed inhibition was only slight, the concentrations of organic matter should not be characterized as the major point for the success of the treatment. For this reason, in terms of conversion capacity, the use of high recirculation ratios is not necessary for a suitable ABR performance.

\section{ACKNOWLEDGEMENTS}

The authors are grateful to the National Council for Scientific and Technological Development (CNPq), grants 142333/2013-1, 233529/2014-4 and 307042/2014-6 (Research Productivity to Dr. Eduardo Cleto Pires), and to the São Paulo Research Foundation (FAPESP), project number 2009/15984-0, for supporting the development of this study. The authors are also grateful to Dr. Vinicius Masquetti da Conceição for his support in reactor monitoring.

\section{REFERENCES}

[1] BNDES, CGEE, 2008. Bioetanol de cana-de-açúcar: energia para o desenvolvimento sustentável. 1 ed. Rio de Janeiro, 316 p. (in Portuguese).

[2] Fuess, L.T., Garcia, M.L., 2014. Implications of stillage land disposal: a critical review on the impacts of fertigation. J. Environ. Manage. 145, 210-229.

[3] Moraes, B.S., Zaiat, M., Bonomi, A., 2015. Anaerobic digestion of vinasse from sugarcane ethanol production in Brazil: challenges and perspectives. Renew. Sust. Energy Rev. 44, 888-903.

[4] Aquino, S., Fuess, L.T., Pires, E.C., 2017. Media arrangement impacts cell growth in anaerobic fixed-bed reactors treating sugarcane vinasse: Structured vs. randomic biomass immobilization. Bioresour. Technol. 235, 219-228. 
[5] Fernández, N., Montalvo, S., Borja, R., Guerrero, L., Sánchez, E., Cortés, I.,

Colmenarejo, M.F., Travieso, L., Raposo, F., 2008. Performance evaluation of an anaerobic fluidized bed reactor with natural zeolite as support material when treating high-strength distillery wastewater. Renew. Energy 33, 2458-2466.

[6] Siqueira, L.M., Damiano, E.S.G., Silva, E.L., 2013. Influence of organic loading rate on the anaerobic treatment of sugarcane vinasse and biogas production in fluidized bed reactor. $J$. Environ. Sci. Heal., A 48(13), 1707-1716.

[7] Del Nery, V., Alves, I., Damianovic, M.H.R.Z., Pires, E.C., 2018. Hydraulic and organic rates applied to pilot scale UASB reactor for sugar cane vinasse degradation and biogas generation. Biomass Bionenergy 119, 411-417.

[8] Ferraz Jr., A.D.N., Koyama, M.H., Araújo Jr., M.M., Zaiat, M., 2016. Thermophilic anaerobic digestion of raw sugarcane vinasse. Renew. Energy 89, 245-252.

[9] Albanez, R., Chiaranda, B.C., Ferreira, R.G., França, A.L.P., Honório, C.D., Rodrigues, J.A.R., Ratusznei, S.M., Zaiat, M., 2016. Anaerobic biological treatment of vinasse for environmental compliance and methane production. Appl. Biochem. Biotechnol. 178, 21-43. [10] Shivayogimath, C.B., Ramanujam, T.K., 1999. Treatment of distillery spentwash by hybrid UASB reactor. Bioprocess Eng. 21, 255-259.

[11] Kumar, G.S., Gupta, S.K., Singh, G., 2007.Biodegration of distillery spent wash in anaerobic hybrid reactor. Water Res. 41, 721-730.

[12] Wilkie, A.C., Riedesel, K.J., Owens, J.M., 2000. Stillage characterization and anaerobic treatment of ethanol stillage from conventional and cellulosic feedstocks. Biomass Bioenergy $19,63-102$.

[13] Weiland, P, Rozzi, A., 1991. The start-up, operation and monitoring of high-rate anaerobic treatment systems: discussers report. Water Sci. Technol. 24(8), 257-277. [14] Cohen, A., Breure, A.M., van Andel, J.G., van Deursen A., 1980. Influence of phase separation on the anaerobic digestion of glucose, I. Maximum COD turn-over rate during continuous operation. Water Res. 14, 1439-1448.

[15] Cohen, A., Breure, A.M., van Andel, J.G.; van Deursen, A., 1982. Influence of phase separation on the anaerobic digestion of glucose, II. Stability and kinetic responses to shock loadings. Water Res, 16, 449-455.

[16]Boncz, M.A., Formagini, E.L., Santos, L.S., Marques, R.D., 2012. Application of urea dosing for alkalinity supply during anaerobic digestion of vinasse. Water Sci. Technol. 66, 2453-2460.

[17] Nandy, T., Shastry, S., Kaul, S.N., 2002. Wastewater management in a cane molasses distillery involving bioresource recovery. J. Environ. Manage. 65, 25-38. 
[18] van Haandel, A.C., 2005. Integrated energy production and reduction of the environmental impact at alcohol distillery plants. Water Sci. Technol., 52(1-2), 49-57. [19]Barrera, E.L., Rosa, E., Spanjers, H., Romero, O., Meester, S.D., Dewulf, J., 2016. A comparative assessment of anaerobic digestion power plants as alternative to lagoons for vinasse treatment: life cycle assessment and exergy analysis. J. Clean. Prod. 113, 459-471. [20] Sarathai, Y., Koottatep, T., Morel, A., 2010. Hydraulic characteristics of an anaerobic bafflled reactor as onsite wastewater treatment system. J. Environ. Sci. 22, 1319-1326. [21]Zhu, G., Lib, J., Wua, P., Jinc, H., Wang, Z., 2008. The performance and phase separated characteristics of an anaerobic baffled reactor treating soybean protein processing wastewater. Bioresour. Technol. 99, 8027-8033.

[22] Henze, M., Harremoës, P., 1983. Anaerobic treatment of wastewater in fixed film reactors: a literature review. Water Sci. Technol. 15(8-9), 1-101.

[23] Grobicki, A.M.W., Stuckey, D.C., 1992. Hydrodynamic characteristics of the anaerobic baffled reactor. Water Res. 26, 371-378.

[24] Nachaiyasit, S., 1995.The effect of process parameters on reactor performance in an anaerobic baffled reactor. $\mathrm{PhD}$ Thesis, Department of Chemical Engineering, Imperial College, London, U.K.

[25] Bachmann, A., Beard, V. L., McCarty, P. L., 1985. Performance characteristics of the anaerobic baffled reactor. Water Res. 19, 99-106.

[26] Chynoweth, D.P., Srivastra V.J., Conrad, J.R., 1980. Research study to determine the feasibility of producing methane gas from sea kelp. Annual Report for General Electric Company, IGT Project 30502, Institute of Gas Technology, Chicago.

[27] Bachmann, A., Beard, V.L., McCarty, P.L., 1983. Comparison of Fixed Film Reactors with a Modified Sludge Blanket Reactor, Fixed Film Biological Processes for Wastewater Treatment, ed. Y. C. Wu and E. D. Smith. Noyes Data, NJ.

[28] Chen, Y., Cheng, J.J., Creamer, K.S., 2008. Inhibition of anaerobic digestion process: A review. Bioresour. Technol. 99, 4044-4064.

[29] APHA, AWWA, WEF, 2005. Standard methods for the examination of water and

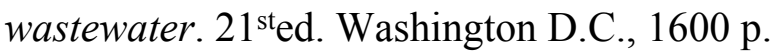

[30] Ripley, L.E., Boyle, W.C., Converse, J.C., 1986. Improved alkalimetric monitoring for anaerobic digestion of high-strength wastes. J. Water Pollut. Control. Fed. 58(5), 406-411. [31] DiLallo, R., Albertson, O.E., 1961. Volatile acids by direct tritation. J Water Pollut Control Fed. 33(4), 356-365.

[32] Alves, I., Del Nery, V., Pozzi, E., Damianovic, M.H.R.Z., Pires, E.C., 2018. Determining the distribution of granule diameter from biological sludge. MethodsX 5, 727-736. 
[33]Döll, M.M.R., Foresti, E., 2010. Effect of the sodium bicarbonate in the treatment of vinasse in AnSBBR operated at 55 and $35^{\circ}$ C. Eng. Sanit. Ambient. 15, 275-282. (in Portuguese).

[34] Vela, F.J., Gianotti, E.P., Foresti, E., Zaiat, M., 1999. Estimation of substrate effective diffusivities in anaerobic bioparticles. Environ. Technol. 20, 1163-1170.

[35] Vieira, L.G.T., Zaiat, M., Foresti, E., 1997. Intrinsic kinetic parameters of substrate utilization by anaerobic sludge along the horizontal-flow anaerobic immobilized sludge (HAIS) reactor. Environ. Technol. 18, 953-957.

[36] Bailey, D.D., Ollis, D.F., 1986. Biochemical Engineering Fundamentals. $2^{\text {nd }}$ edition. New York: McGraw-Hill.

[37] Crank, J., 1975. The mathematics of diffusion. $2^{\text {nd }}$ edition. Oxford: Clarendon Press. [38] Monod, J., 1950. La technique de culture continue, theorie et applications. Ann. Inst. Pasteur, 79(4), 390-410.

[39] Andrews, J.F., 1968. A mathematical model for the continuous culture of microorganisms utilizing inhibitory substrates. Biotechnol. Bioeng. 10(6), 707-723.

[40] Wu, M., Hickey, R., 1997. Dynamic model for UASB reactor including reactor hydraulics, reaction, and diffusion. J. Environ. Eng. 123, 244-252.

[41] Schmidt, L., 1998. The Engineering of Chemical Reactions. Oxford University Press. [42] Levenspiel, O., 1999. Chemical Reaction Engineering. $3^{\text {rd }}$ Edition. New York: John Wiley \& Sons.

[43] Speece, R.E., 1981. Review - Environmental requirements for anaerobic digestion of biomass. Environmental Studies Institute, Drexel University, Philadelphia.

[44]Fuess, L.T., Kiyuna, L.S.M., Ferraz Jr., A.D.N., Persinoti, G.F., Squina, F.M., Garcia, M.L., Zaiat, M., 2017. Thermophilic two-phase anaerobic digestion using innovative fixedbed reactor for enhanced organic matter removal and bioenergy recovery from sugarcane vinasse. Appl. Energy 189, 480-491.

[45] Mosey, F.E., 1983. Mathematical modeling of the anaerobic digestion process: regulatory mechanisms for the formation of short-chain volatile acids from glucose. Water Sci. Technol. 15(8-9), 209-232.

[46]Fuess, L.T., Araújo Jr., M.M., Garcia, M.L., Zaiat, M., 2017. Designing full-scale biodigestion plants for the treatment of vinasse in sugarcane biorefineries: how phase separation and alkalinization impact biogas and electricity production costs? Chem. Eng. Res. Des. 119, 209-220.

[47] von Sperling, M., 2007. Wastewater characteristics, treatment and disposal. London: IWA Publishing. 
[48] Mohana, S., Acharya, B.K., Madamwar, D., 2009. Distillery spent wash: treatment technologies and potential applications. J. Hazard. Mater. 163, 12-25.

[49] Chandra, R., Bharagava, R.N., Rai, V., 2008. Melanoidins as major colourant in sugarcane molasses based distillery effluent and its degradation. Bioresour. Technol. 99, 4648-4660.

[50] Syaichurrozi, I., Budiyono, Sumardiono, S., 2013. Predicting kinetic model of biogas production and biodegradability organic materials: biogas production from vinasse at variation of COD/N ratio. Bioresour. Technol. 149, 390-397

[51] Kiyuna, L.S.M., Fuess, L.T., Zaiat, M., 2017. Unraveling the influence of the $\mathrm{COD} /$ sulfate ratio on organic matter removal and methane production from the biodigestion of sugarcane vinasse. Bioresour. Technol. 232, 103-112. 
(a)

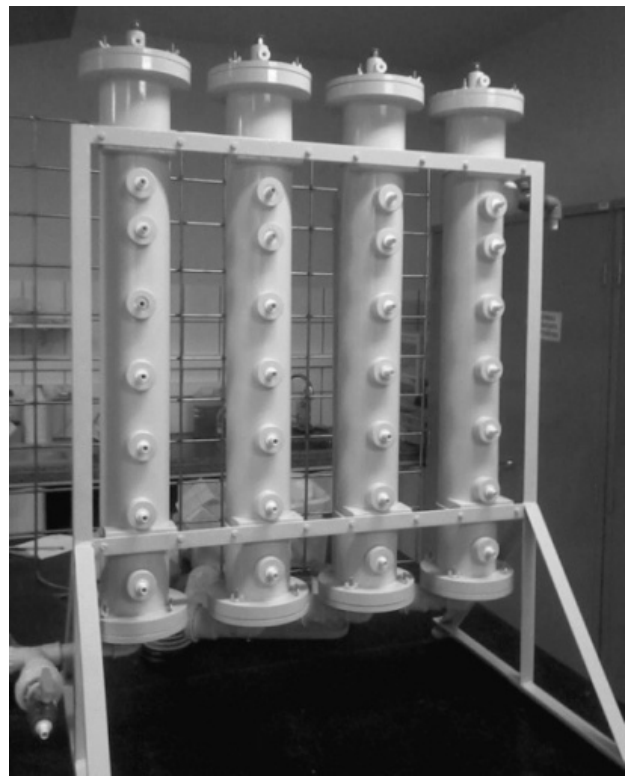

(b)

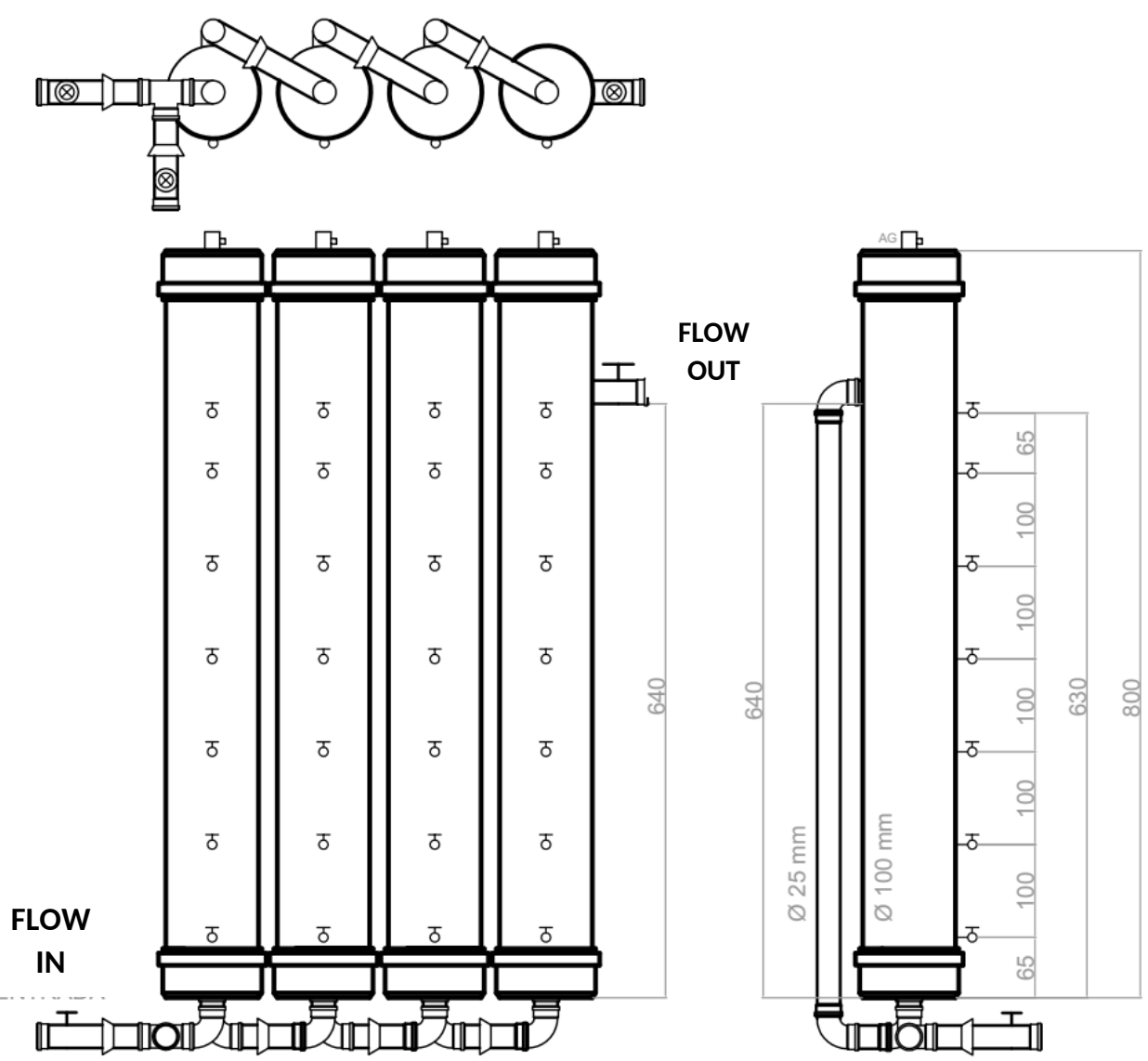

Figure 1. Details of the bench-scale anaerobic baffled reactor: (a) PVC-built prototype and (b) sketch with overall dimensions. 


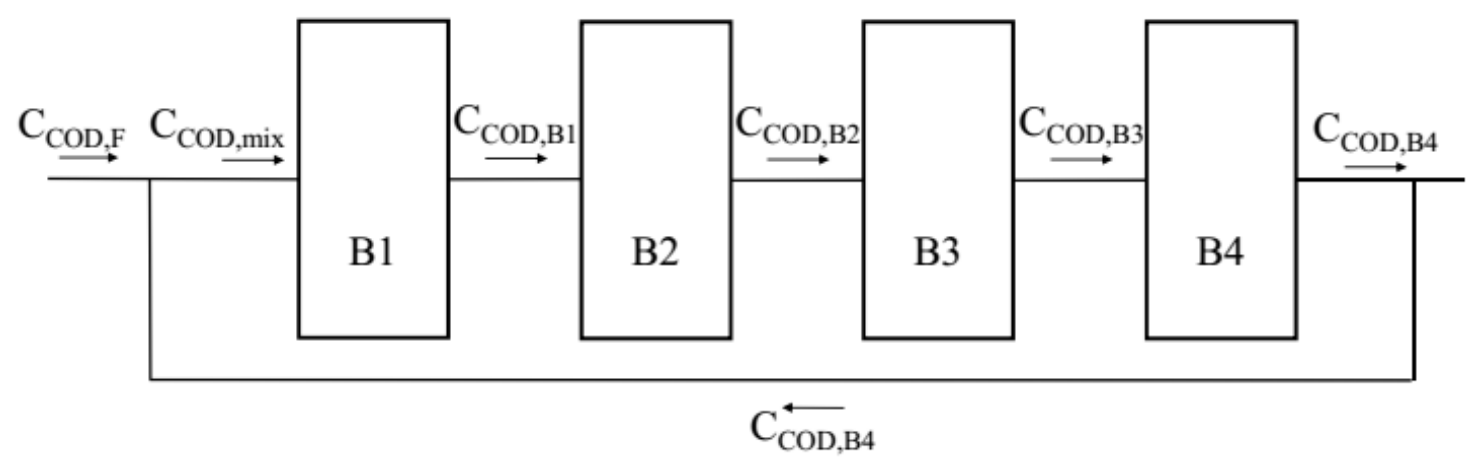

Figure 2. Graphical representation of the model used to describe COD conversion in the ABR. Legend: $\mathrm{C}_{\mathrm{COD}}$ - organic matter concentration as $\mathrm{COD}, \mathrm{F}$ - feeding stream, mix - mixing, $\mathrm{B} 1-$ 4 - baffles 1 to 4 . 

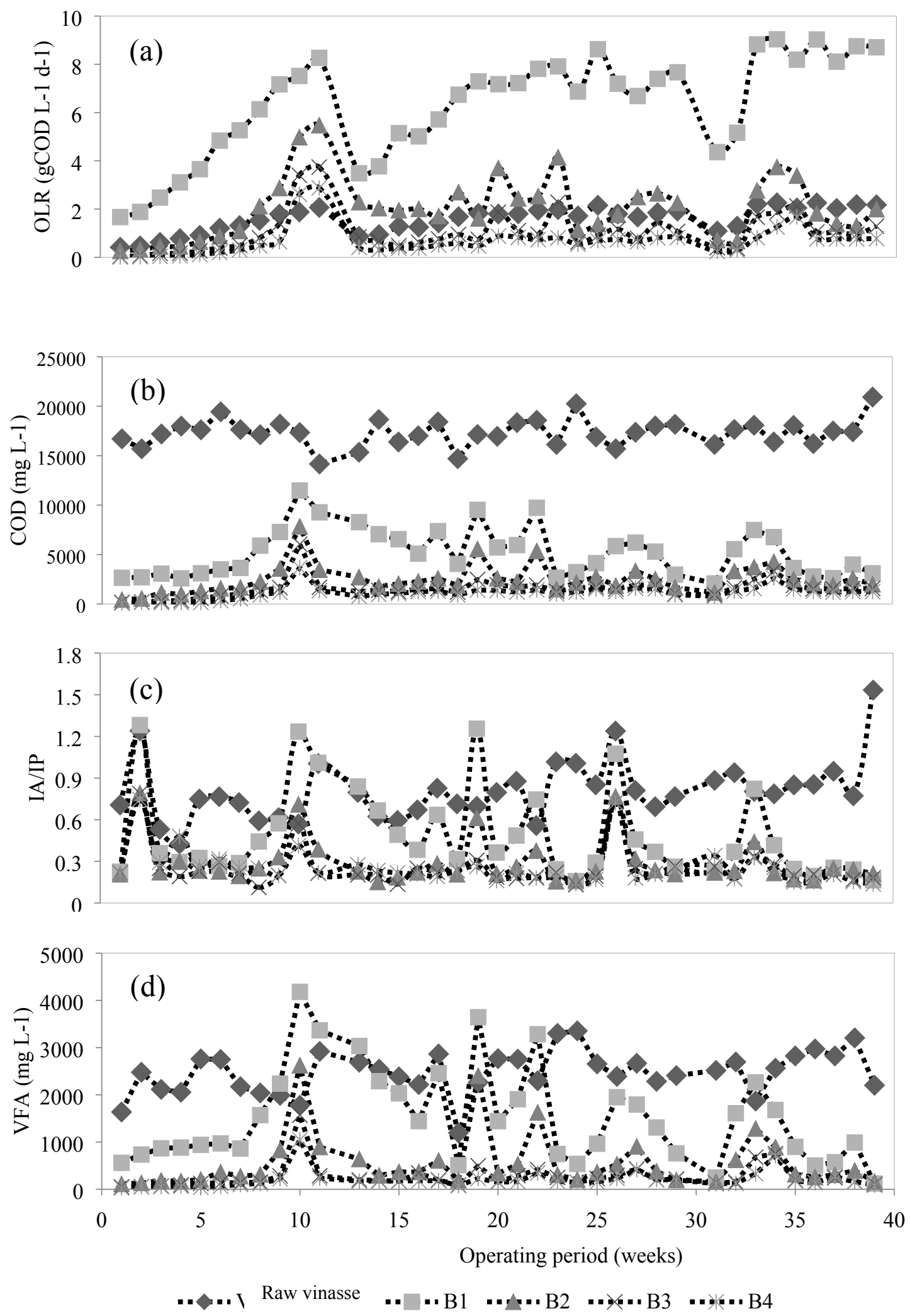

Figure 3. Overall performance of the ABR: (a) applied OLR, (b) organic matter concentration profiles as COD, (c) IA/PA ratio and (d) VFA concentrations. 


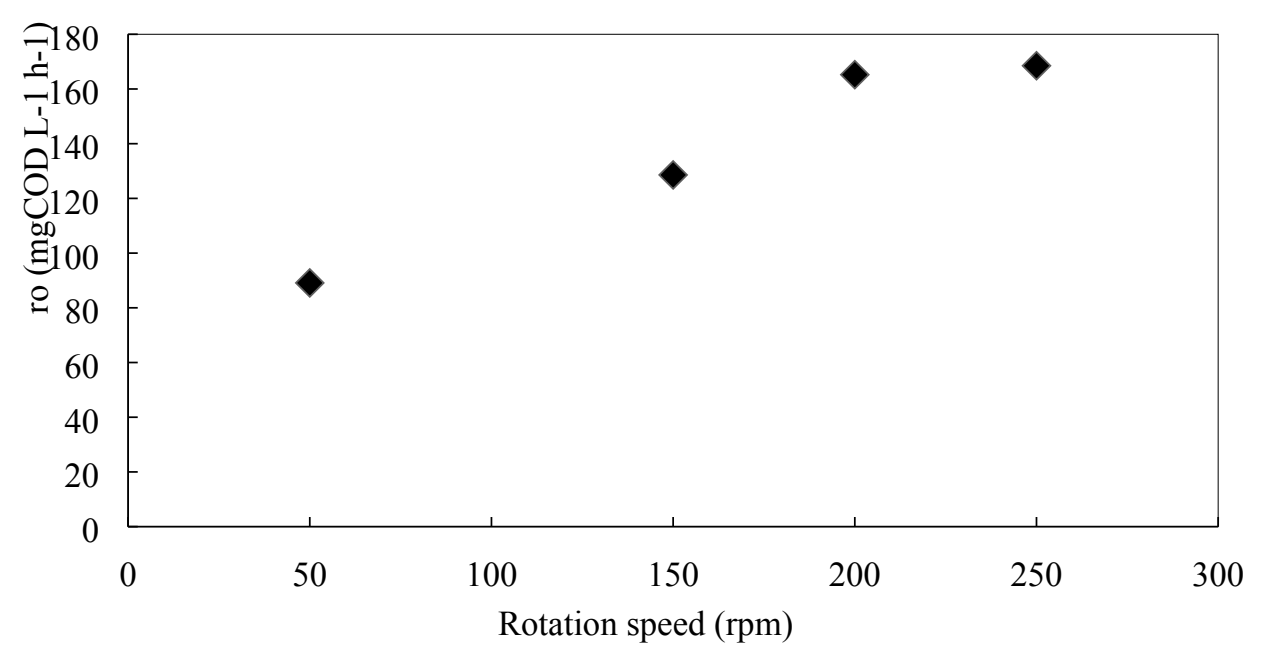

(a)

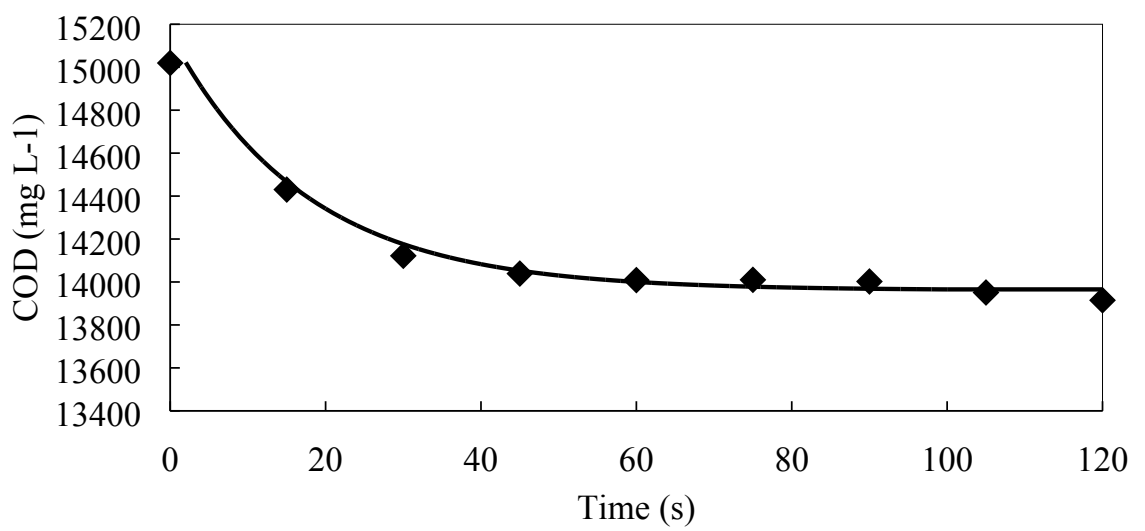

Figure 4. Kinetic assessment details: (a) initial reaction rate $\left(r_{o}\right)$ at different mixing conditions and (b) temporal profiles of COD decay due to the diffusion of sugarcane vinasse into the UASB granules. Legend: $(\diamond)$ experimental data, $(\square)$ fitted equation $\left(\mathrm{R}^{2}=0.9917\right)$. 


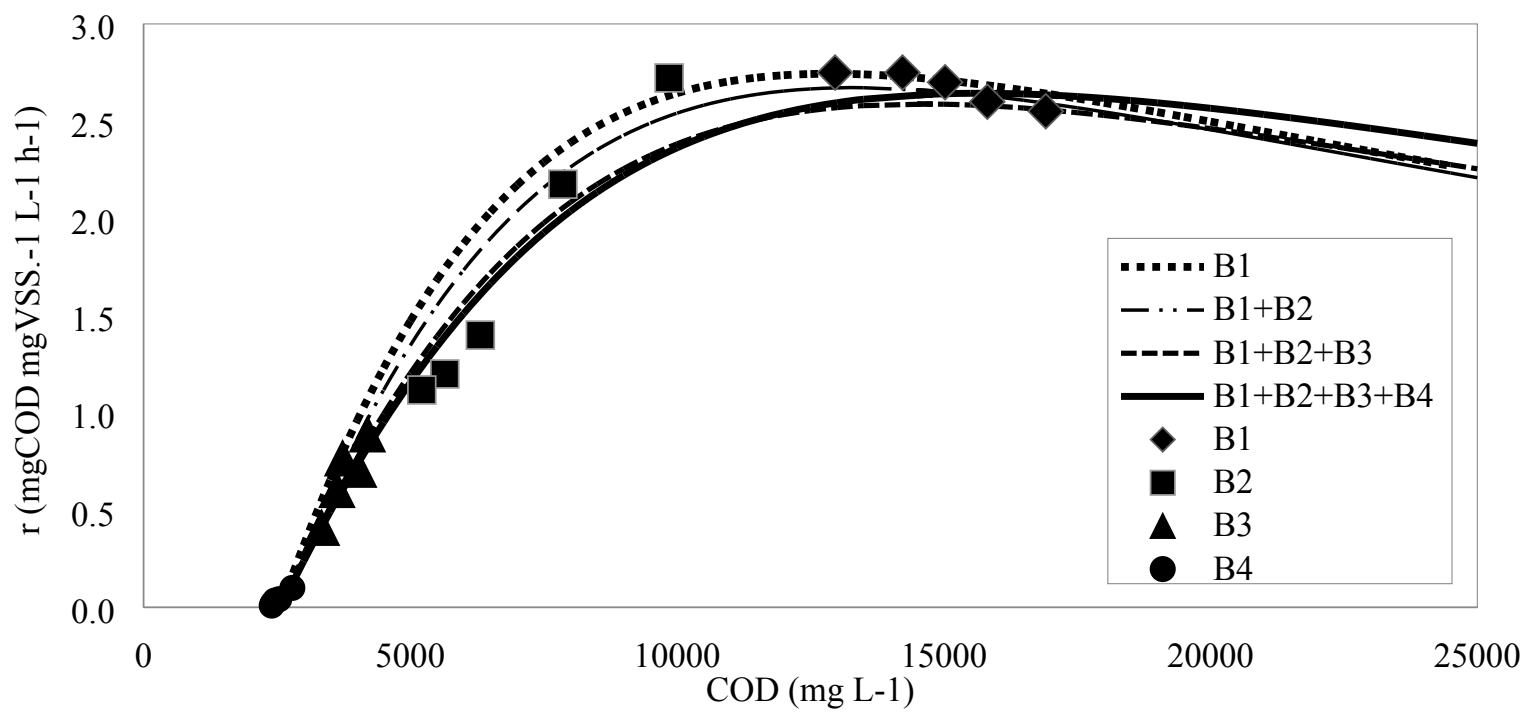

Figure 5. Kinetic models for different combinations of baffles. 

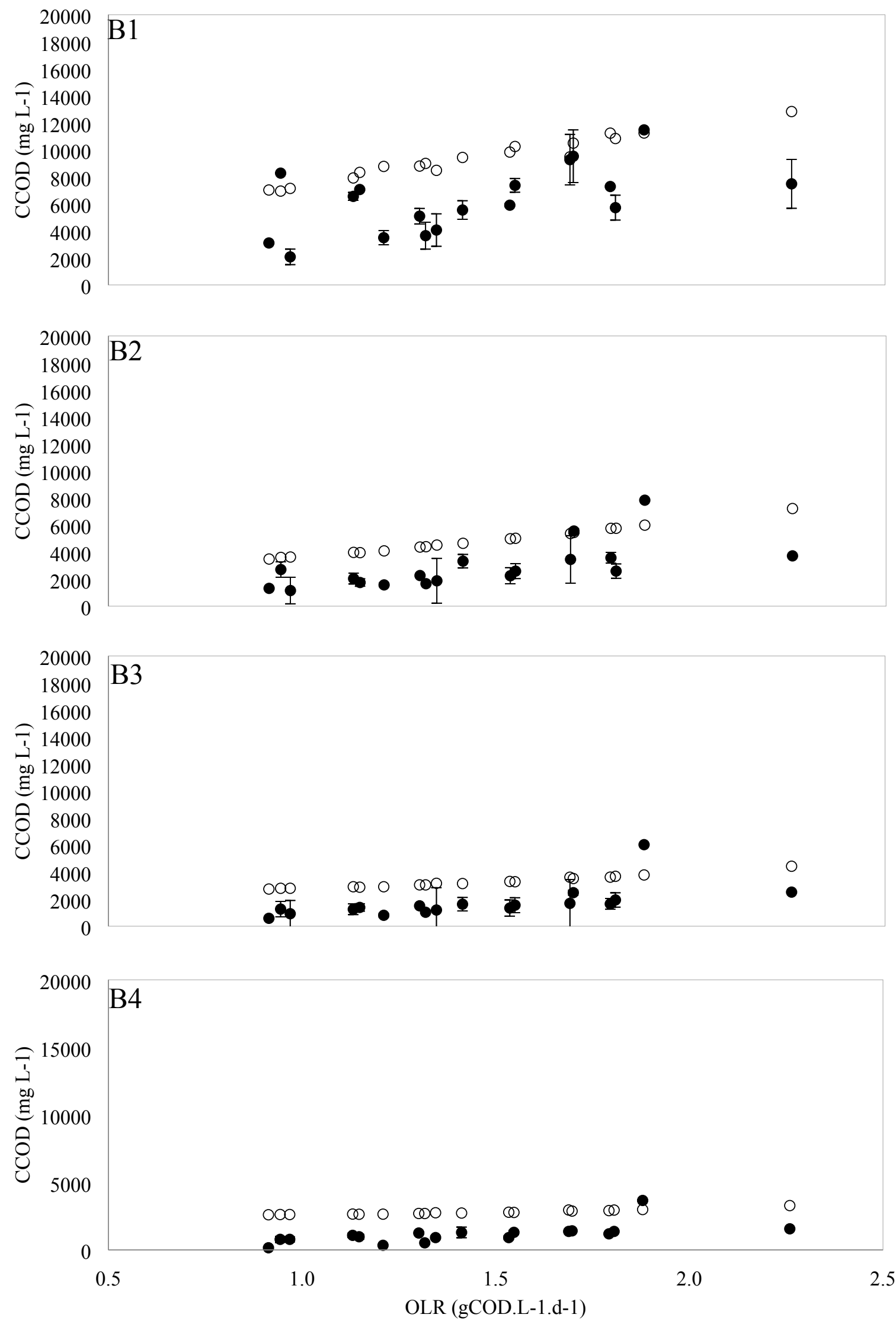

Figure 6. Comparison between experimental data $(\bullet)$ and model results $(\circ)$ for COD profiles in B1, B2, B3 and B4. 

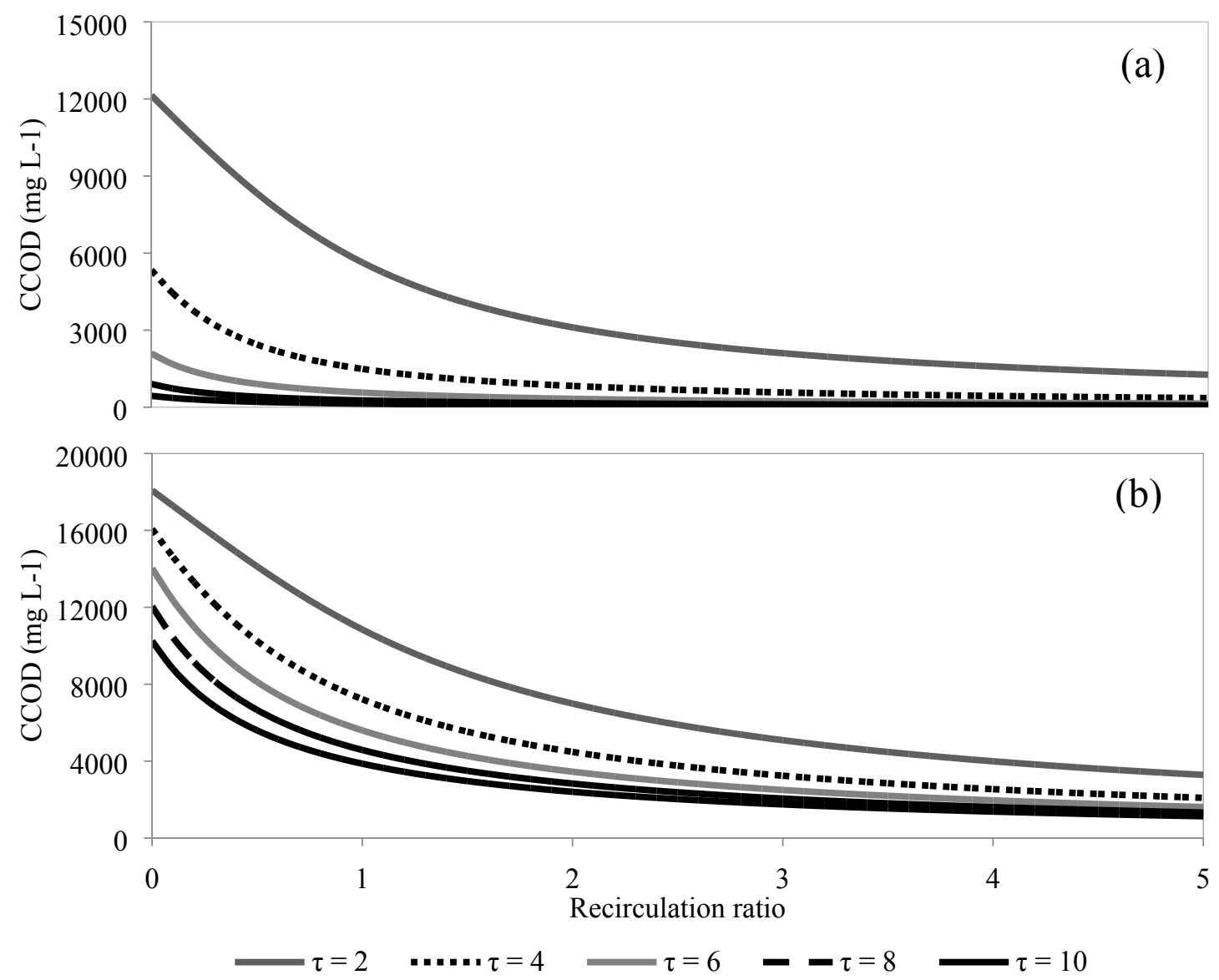

Figure 7. COD decay profiles for different hydraulic retention time $(\tau)$ values and recirculation ratios in (a) B4 and (b) B1. 
Table 1. COD/BOD ratio for sugarcane vinasse at different steps of the processing in the ABR.

\begin{tabular}{llll}
\hline Sample & BOD $\left(\mathrm{mg} \mathrm{L}^{-1}\right)$ & COD $\left(\mathrm{mg} \mathrm{L}^{-1}\right)$ & COD/BOD (-) \\
\hline Raw vinasse & 8500 & 18400 & 2.16 \\
B1 effluent & 680 & 4640 & 6.83 \\
B2 effluent & 310 & 2430 & 7.84 \\
B3 effluent & 210 & 1768 & 8.81 \\
B4 effluent & 130 & 914 & 7.03 \\
\hline
\end{tabular}


Table 2. Effective diffusivity $\left(\mathrm{D}_{\mathrm{e}}\right)$ obtained for different organic substrates in anaerobic biofilms.

\begin{tabular}{llll}
\hline $\begin{array}{l}\text { Sludge immobilization } \\
\text { method }\end{array}$ & Substrate & $\mathrm{D}_{\mathrm{e}}\left(\mathrm{cm}^{2} \mathrm{~s}^{-1}\right)$ & Reference \\
\hline Alginate gel & Glucose & $(0.58 \pm 0.01) \times 10^{-5}$ & {$[34]$} \\
& Sucrose & $(1.06 \pm 0.40) \times 10^{-5}$ & {$[34]$} \\
& Acetate & $(1.49 \pm 0.04) \times 10^{-5}$ & {$[34]$} \\
Self-immobilization & Sugarcane vinasse & $(1.26 \pm 0.20) \times 10^{-5}$ & This study \\
(granules) & & & \\
\hline
\end{tabular}


Table 3. Kinetic characterization of the organic matter conversion (as COD) in the four baffles of the ABR.

\begin{tabular}{|c|c|c|c|c|c|c|}
\hline \multirow[t]{2}{*}{ Baffle } & \multirow[t]{2}{*}{ Kinetic model } & \multicolumn{5}{|c|}{ Kinetic parameter } \\
\hline & & $\mathrm{r}_{\max }^{\mathrm{a}}$ & $\mathrm{K}_{\mathrm{S}}^{\mathrm{b}}$ & $\mathrm{K}_{\mathrm{i}}^{\mathrm{b}}$ & $\mathrm{k}^{\mathrm{a}}$ & $\mathrm{C}_{\mathrm{res}}^{\mathrm{b}}$ \\
\hline B1 & $\begin{array}{l}\text { Inhibition by substrate excess } \\
\text { (Equation } 10 \text { ) }\end{array}$ & 9.12 & 11980 & 8874 & - & 2362 \\
\hline B2 & $\begin{array}{l}\text { First-order with residual } \\
\text { (Equation 7) }\end{array}$ & - & - & - & $4.1 \times 10^{-4}$ & - \\
\hline B3 & $\begin{array}{l}\text { First-order with residual } \\
\text { (Equation 7) }\end{array}$ & - & - & - & $4.6 \times 10^{-4}$ & - \\
\hline B4 & $\begin{array}{l}\text { First-order with residual } \\
\text { (Equation 7) }\end{array}$ & - & - & - & $2.6 \times 10^{-4}$ & - \\
\hline
\end{tabular}

Notes: ${ }^{\mathrm{a}} \mathrm{mgCOD} \mathrm{mgVSS}^{-1} \mathrm{~L}^{-1} \mathrm{~d}^{-1},{ }^{\mathrm{b}} \mathrm{mgCOD} \mathrm{L}{ }^{-1}$. 


\section{EFFECTS OF RECIRCULATION IN ANAEROBIC BAFFLED REACTORS}

Guilherme Araujo Vuitik ${ }^{\mathrm{a},{ }^{*}}$, Lucas Tadeu Fuess ${ }^{\mathrm{a}}$, Valeria Del Nery ${ }^{\mathrm{a}, \mathrm{b}}$, René BañaresAlcántara $^{\mathrm{c}}$, Eduardo Cleto Pires ${ }^{\mathrm{a}, \mathrm{b}}$

${ }^{a}$ Biological Processes Laboratory, São Carlos School of Engineering, University of São Paulo (LPB/EESC/USP). Av. João Dagnone 1100, São Carlos, São Paulo 13563-120, Brasil. Emails: guilhermevuitik@gmail.com; 1tfuess@alumni.usp.br

${ }^{b}$ Department of Hydraulics and Sanitary Engineering, São Carlos School of Engineering, University of São Paulo (SHS/EESC/USP). Av. Trabalhador São-Carlense 400, São Carlos, São Paulo 13566-590, Brasil. E-mails: vdelnery@terra.com.br, ecpires@sc.usp.br

${ }^{c}$ Department of Engineering Science, University of Oxford. Parks Road, Oxford OX1 3PJ, United Kingdom. E-mail: rene.banares@eng.ox.ac.uk

(*) Corresponding author 
Table S1. Average diameters measured in anaerobic granules collected from different baffles.

\begin{tabular}{ll}
\hline Baffle & Diameter $(\mathrm{mm})$ \\
\hline B1 & $1.89 \pm 0.59$ \\
B2 & $1.76 \pm 0.61$ \\
B3 & $1.96 \pm 0.60$ \\
B4 & $1.76 \pm 0.68$ \\
\hline Average & $1.74 \pm 0.32$ \\
\hline
\end{tabular}

Note: ANOVA analysis indicated that the differences among the average diameters are significant in more than $5 \%\left(\mathrm{~F}=65.27>\mathrm{F}_{\mathrm{CRIT}}=2.61\right)$. 